\title{
SURVEI HIDRO-OSEANOGRAFI DI PERAIRAN RAJA AMPAT, PAPUA BARAT, INDONESIA
}

\author{
HYDRO-OCEANOGRAPHIC SURVEY AT \\ RAJA AMPAT WATERS, WEST PAPUA, INDONESIA
}

\author{
Athur Yordan Herwindya*, Hendra Kurnia Febriawan, \\ Adam Budi Nugroho dan Arnold Dannari \\ Balai Teknologi Survei Kelautan, Badan Pengkajian dan Penerapan Teknologi (BPPT), \\ J1. MH. Thamrin No. 8, Jakarta \\ *E-mail: athur.yordan@bppt.go.id
}

\begin{abstract}
ABSTRAK
Kepulauan Raja Ampat merupakan salah satu tujuan wisata utama di Indonesia dan juga sebagai kawasan konservasi alam. Hal tersebut disebabkan karena wilayah tersebut kaya akan keanekaragaman hayati, kenampakan dan sumber daya alam, serta budaya. Pada tahun 2014, pemerintah Indonesia menyelenggarakan kegiatan Sail Raja Ampat sebagai bagian promosi pembangunan di wilayah tersebut. Badan Pengkajian dan Penerapan Teknologi (BPPT) berperan dalam kegiatan Sail tersebut dengan menggunakan KR Baruna Jaya IV untuk melakukan survei kelautan maupun kegiatan diseminasi teknologi. Penelitian ini bertujuan untuk memberikan gambaran kegiatan survei hidro-oseanografi di perairan Raja Ampat sebagai bagian kegiatan Sail Raja Ampat. Kegiatan survei dilakukan pada dua area utama yaitu Teluk Kabui dan Selat Sagewin. Hasil menunjukkan bahwa survei tersebut mampu memberikan gambaran morfologi di kedua area tersebut. Secara batimetri perairan Teluk Kabui memiliki kedalaman antara 18 - 53 meter, sedangkan kedalaman perairan Selat Sagewin berkisar antara 104 - 508 meter. Rata - rata suhu di perairan Raja Ampat diketahui berkisar antara $29.2^{\circ}-30.5^{\circ} \mathrm{C}$ dan memiliki salinitas berkisar antara 31 - 34 psu. Litologi berupa batupasir, batugamping, dan lempung juga berhasil diketahui dari survei tersebut. Data - data ilmiah kebumian tersebut bermanfaat untuk melengkapi data data yang sudah ada ataupun sebagai dasar perencanaan kegiatan penelitian selanjutnya. Disamping itu, data tersebut dapat dimanfaatkan untuk mengetahui karakteristik alam di perairan Raja Ampat sebagai pendukung kegiatan pembangunan di wilayah tersebut.
\end{abstract}

Kata Kunci: Raja Ampat, hidrografi, oseanografi, multibeam, CTD, sub bottom profiler

\begin{abstract}
[Hydro-oceanographic Survey at Raja Ampat Waters, West Papua, Indonesia] Raja Ampat archipelago is one of the major tourism destinations in Indonesia and a nature conservation area. This is due to the abundance of biodiversity, natural features and resources, as well as culture. In 2014, the Indonesian government organized Sail Raja Ampat as a promotion program for the development of Raja Ampat. Badan Pengkajian dan Penerapan Teknologi (BPPT) took part in the event by using $R V$ Baruna Jaya IV to perform a marine survey and technological dissemination activity. This study is aimed to describe hydro-oceanographic survey activity at the Raja Ampat waters as a part of the Sail Raja Ampat. The survey was conducted at the two main areas: Teluk Kabui and Selat Sagewin. Results indicate that the survei has successfully revealed morphological features in both areas. The bathymetry shows that Teluk Kabui has a bathymetry depth of $18-53$ meters, while the bathymetry of Selat Sagewin is about $104-508$ meters. The average temperature of the region is approximately $29.2^{\circ}-30.5^{\circ} \mathrm{C}$ with a salinity of $31-34$ psu. Lithological features as sandstones, limestones, and clays were also obtained. Those results and data are useful to complement the existing data and to future research activities. In addition, the data could also be used to evaluate the natural characteristics of Raja Ampat waters and to support the development activity in that area.
\end{abstract}

Keywords: Raja Ampat, hydrography, oceanography, multibeam, CTD, sub bottom profiler 


\section{PENDAHULUAN}

Wilayah kepulauan Raja Ampat merupakan salah satu kabupaten yang berada di Provinsi Papua Barat, Indonesia. Kepulauan ini terdiri dari empat kepulauan utama yaitu Waigeo, Batanta, Salawati, dan Misool beserta ratusan pulau - pulau kecil (Larsen et al., 2018). Wilayah kepulauan Raja Ampat merupakan pusat dari segitiga terumbu karang "coral triangle" dunia yang sangat kaya keanekaragaman terumbu karang. Hukom et al. (2018) memprediksi bahwa terdapat sekitar 474 spesies ikan terumbu karang, 456 spesies terumbu keras (hard coral), dan juga 699 spesies moluska di wilayah tersebut. Disamping itu, wilayah ini juga merupakan titik konsentrasi dari habitat Cetacea seperti ikan paus, dan spesies lain seperti penyu, hiu, dugong, dan lumba - lumba (Papilaya et al., 2019). Priatna \& Sadhotomo (2011) juga menyebutkan bahwa gugusan terumbu karang di wilayah tersebut juga berpengaruh pada ekosistem ikan - ikan pelagis. Keanekaragam ekosistem yang lain juga terdapat di wilayah tersebut seperti padang lamun, hutan mangrove, dan pantai - pantai tebing berbatu (Papilaya et al., 2019). Secara oseanografi dan biogeografi, Donnelly et al. (2003) menjelaskan bahwa wilayah kepulauan Raja Ampat terletak pada batas barat wilayah Samudra Pasifik di khatulistiwa dan pada jalur masuk timur laut "Indonesian Throughflow"dari Samudra Pasifik ke Samudra Hindia sehingga menarik untuk dijadikan kajian ilmiah. Secara geologi mereka juga menyebutkan bahwa Selat Sagewin, yang merupakan pembatas dua continental shelf, merupakan objek kajian ilmiah yang menarik karena diduga terdapat Sesar Sorong di area tersebut.

Kepulauan Raja Ampat saat ini berkembang menjadi kawasan konservasi dan tujuan wisata nasional dan internasional. Dari beberapa pilihan kegiatan wisata, kegiatan penyelaman merupakan kegiatan utama wisatawan di kawasan Raja Ampat. Papilaya et al. (2019) menemukan sedikitnya ada 15 lokasi penyelaman yang terkenal bagi wisatawan dengan jumlah penyelam berkisar antara 20 - 500 penyelam per hari. Ditambah lagi kegiatan - kegiatan wisata lain di wilayah tersebut menyebabkan adanya potensi wisata dan pembangunan yang harus ditingkatkan di kepulauan Raja Ampat. Untuk lebih menggalakkan program pariwisata dan pembangunan di Raja Ampat, pemerintah menyelenggarakan kegiatan Sail Raja Ampat pada Tahun 2014. Pada kegiatan Sail Raja ampat tersebut, berbagai kegiatan lintas kementerian dan lembaga serta pemerintah daerah telah ditetapkan dan menjadi bagian keberhasilan program pemerintah, khususnya mendukung Propinsi Papua Barat sebagai destinasi utama pariwisata dunia. Balai Teknologi Survei Kelautan, Badan Pengkajian dan Penerapan Teknologi (BPPT) terlibat secara aktif dalam rangkaian Sail Raja Ampat 2014 tersebut. Dengan menggunakan Kapal Riset (KR.) Baruna Jaya IV, BPPT berpartisipasi dalam rangkaian kegiatan, khususnya dalam bidang kegiatan ekspedisi kapal riset dan ilmiah kelautan. Salah satu kegiatan ilmiah kelautan dalam Sail Raja Ampat tersebut adalah kegiatan survei hidro-oseanografi. Disamping itu terdapat ekspedisi kapal berupa pengenalan dan diseminasi kapal dan peralatan riset kelautan kepada pejabat dan masyarakat sekitar Raja Ampat.

Penelitian ini bertujuan untuk mendeskripsikan kegiatan survei hidro-oseanografi di perairan Raja Ampat, Papua Barat, Indonesia. Survei hidro-oceanografi tersebut terdiri dari beberapa kegiatan survei sepertisurvei multibeam batimetri, survei oseanografi (suhu dan salinitas), dan survei sub bottom profiler (SBP) yang merupakan kegiatan utama dari ekspedisi riset Sail Raja Ampat tersebut. Kegiatan survei hidrooseanografi tersebut diharapkan dapat memberikan data ilmiah kebumian sebagai 
pelengkap data - data ilmiah yang sudah ada dan untuk mendukung program pembangunan di wilayah Raja Ampat, Papua Barat, Indonesia.

\section{METODOLOGI}

\subsection{Lokasi Studi}

Lokasi studi terletak di Kecamatan Waisai, Raja Ampat dengan koordinat area survei $02^{\circ} 00^{\prime} \mathrm{S}$ hingga $00^{\circ} 00^{\prime} \mathrm{N}$ dan $129^{\circ} 00^{\prime} \mathrm{E}$ hingga $131^{\circ} 00^{\prime} \mathrm{E}$ tepatnya di perairan Teluk Kabui dan Selat Sagewin, seperti terlihat pada Gambar 1. Kegiatan survei dilaksanakan selama 28 hari, mulai tanggal 17 Agustus sampai dengan 20 September 2014 menggunakan Kapal Riset Baruna Jaya IV.

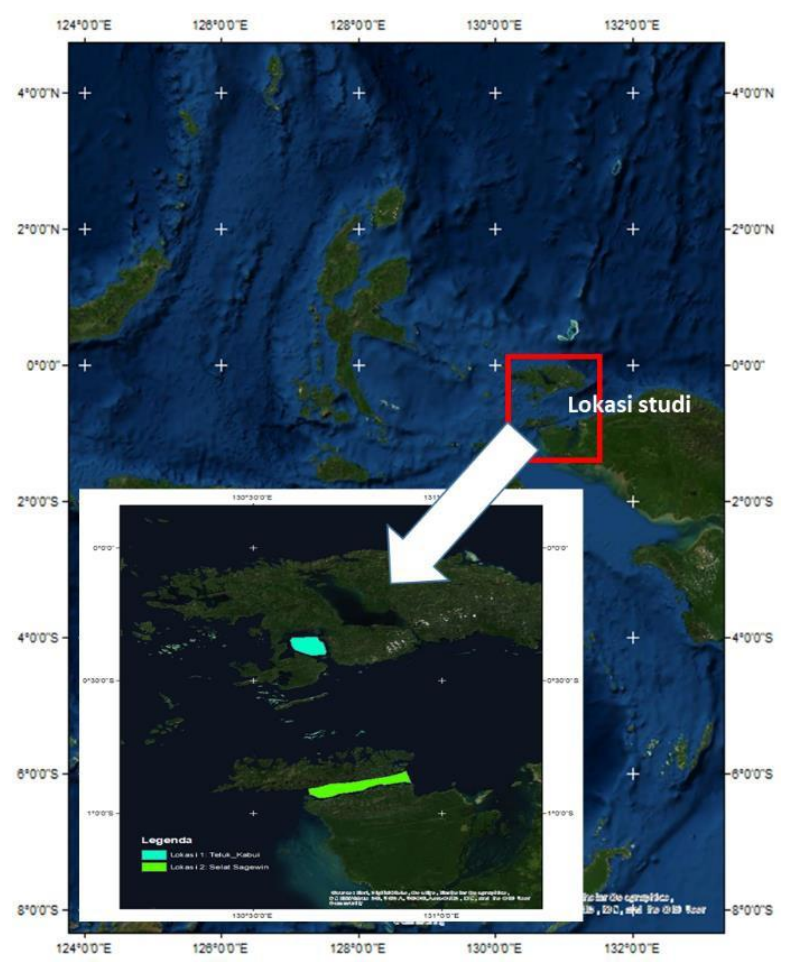

Gambar 1. Lokasi penelitian

Pada survei tersebut, kegiatan navigasi dan penentuan posisi merupakan salah satu aspek penting dari keseluruhan kegiatan. Salah satu parameter dalam penentuan posisi tersebut adalah pemilihan datum geodesi dan proyeksi peta. Pada survei tersebut digunakan datum global WGS-84 dengan sistem proyeksi Universal Transverse Mercator (UTM) zone 52S. Oleh karena itu, penentuan posisi pada kegiatan survei batimetri dan survei oseanografi selanjutnya akan bereferensi pada datum tersebut.

\subsection{Penentuan Posisi dan Navigasi}

Sistem penentuan posisi dan navigasi yang digunakan pada K.R. Baruna Jaya IV adalah DGPS F180 Coda Octopus. Sistem penentuan posisi tersebut merupakan sistem yang terintegrasi antara sistem penentuan posisi (koordinat) dan juga sistem pengukur pergerakan kapal (inertial motion unit/IMU) (Codaoctopus, 2020). Sistem tersebut 
terdiri dari alat IMU dan dual-antenna GPS receiver. Coda Octopus F180 berfungsi untuk mendapatkan data arah (heading), dan data pergerakan inersial kapal (attitude) yang terdiri dari roll, pitch, yaw, dan heave. Menurut Sade et al. (2011), sistem tersebut dapat menghasilkan data pitch dan roll dengan ketelitian $0.02^{\circ}$, data heave dengan ketelitian $1.25 \mathrm{~mm}$, dan data heading dengan ketelitian $\sim 0.06^{\circ}$. Sistem kalibrasi dari sistem navigasi inersial ini menggunakan metode perhitungan yang didasarkan pada solusi aljabar linear. Algoritma perhitungan yang digunakan adalah 23-state Kalman filter. Algoritma ini dapat mengontrol data masukan dari GPS dan gerakan inersial secara real time untuk menghasilkan keluaran yang diperoleh dengan menghitung nilai prediksi yang akurat. Selain itu algoritma ini dapat mereduksi solusi navigasi GPS dan kesalahan drift yang dihasilkan dari sensor inersial. Dengan demikian untuk mendapatkan nilai kalibrasi dari alat ini cukup dilakukan dengan mengaktifkan alat ini yang sudah terpasang stabil di wahana kapal yang terus bergerak. Febriawan et al. (2020) menggunakan sistem penentuan posisi teliti tersebut dalam studi tentang investigasi kapal tenggelam di Teluk Lamong, Surabaya.

Untuk keperluan navigasi survei, sistem penentuan posisi tersebut dihubungkan ke perangkat lunak navigasi Hypack versi 6.2a (Gambar 2). Hypack ini terdiri dari dua bagian yaitu layar administrator dan layar survei. Layar administrator digunakan untuk menentukan desain survei seperti proyeksi geodetik, lajur survei, peta dasar, alat yang digunakan, dan tipe datanya. Layar survei digunakan untuk petunjuk arah kapal dan akusisi data hidrografi. Data navigasi disimpan dalam ukuran yang presisi $(<1 \mathrm{mSec})$, sehingga memungkinkan untuk melakukan perekaman data secara kontinyu.

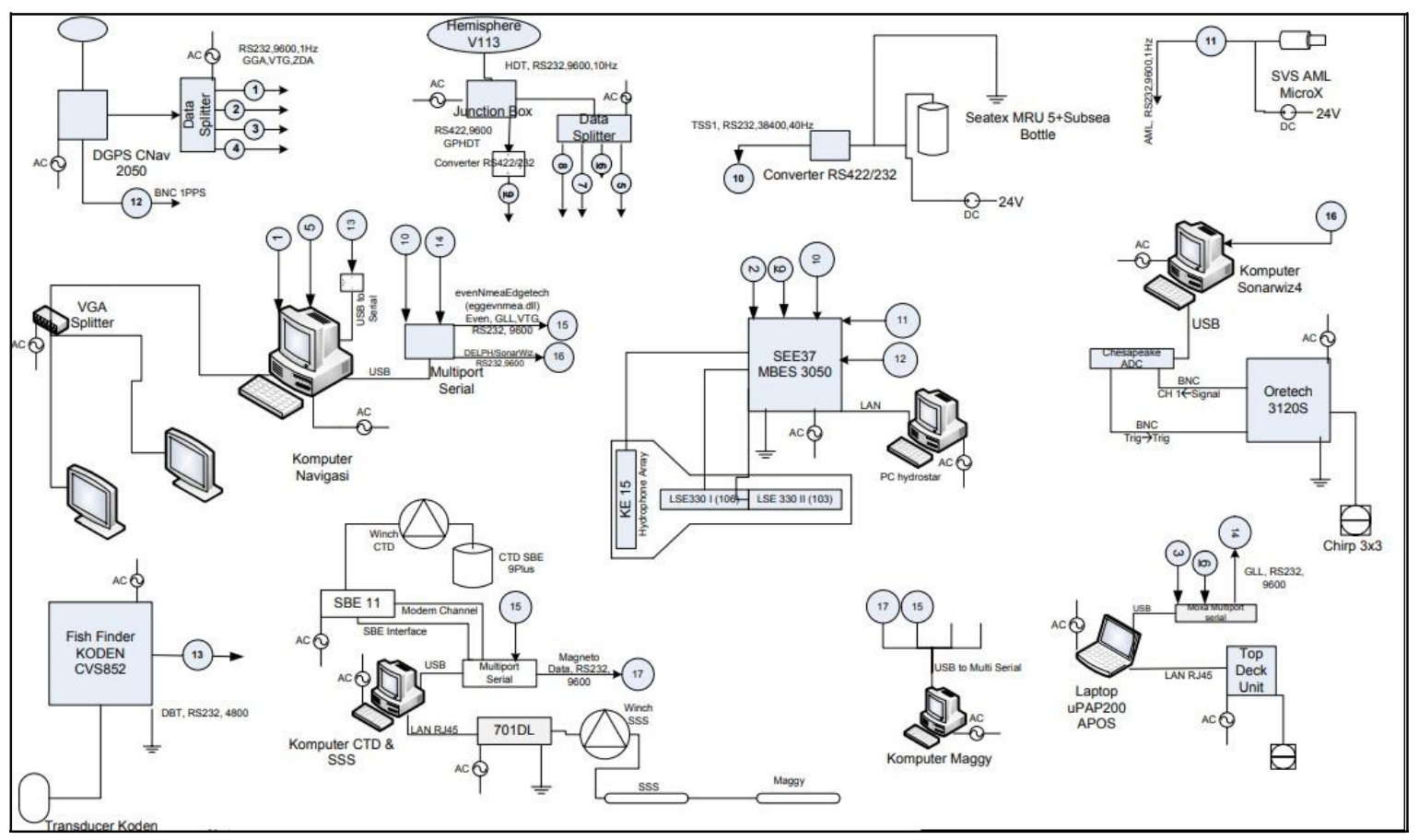

Gambar 2. Diagram sistem akuisisi peralatan survei pada Baruna Jaya IV.

\subsection{Survei Batimetri}

Survei multibeam echosounder bertujuan untuk memetakan kedalaman (batimetri) di daerah survei. Sistem multibeam echosounder (MBES) Elac Seabeam 1050D digunakan pada kegiatan penelitian ini. Sistem multibeam ELAC SeaBeam 1050D 
tersebut mempunyai daya jangkau sapuan yang dapat disesuaikan dengan sudut pancaran yang diatur sebesar $153^{\circ}, 131^{\circ}, 108^{\circ}, 86^{\circ}, 63^{\circ}$, dan $41^{\circ}$. Dengan sudut tersebut dapat dicapai jangkauan (coverage) kedalaman masing-masing sebesar 8.3 kali kedalaman, 4.4 kali kedalaman, 2.7 kali kedalaman, 1.9 kali kedalaman, 1.2 kali kedalaman, dan 0.7 kali kedalaman. Gambar 3 merupakan ilustrasi dari perhitungan coverage tersebut, untuk kedalaman 500 meter dan sudut pancaran $153^{\circ}$ akan didapat jangkauan lebar swath sekitar 4100 meter, sedangkan untuk kedalaman 1000 meter dengan sudut pancaran $131^{\circ}$ akan didapat jangkauan selebar 4400 meter.

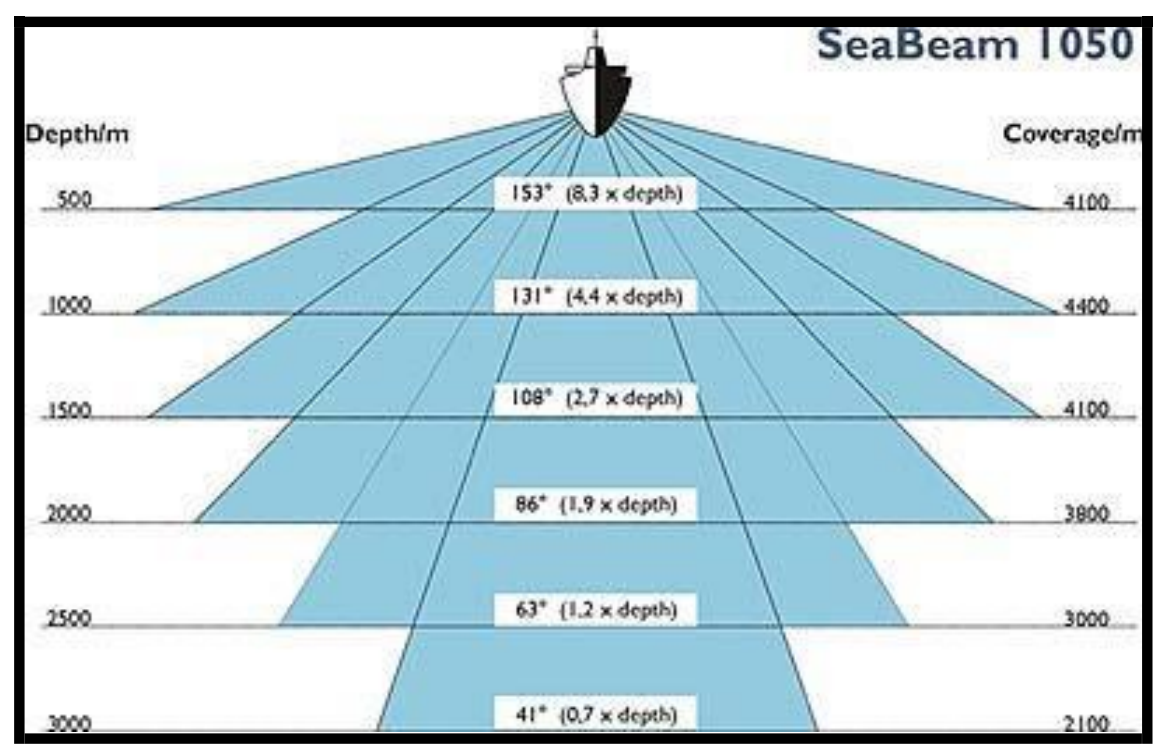

Gambar 3. Ilustrasi lebar sapuan MBES berdasarkan kedalaman dan sudut.

Pada akuisisi data MBES diperlukan data pengukuran sound velocity profile (SVP) untuk koreksi data kedalaman akibat deviasi perambatan sinyal akustik di dalam air karena perbedaan indeks bias lapisan air (water column). Sehingga dengan data SVP ini diharapkan deviasi yang terjadi menjadi minimal. Data SVP bisa didapatkan dari data hasil pengukuran SVP atau dari data hasil pengukuran CTD. Data SVP tersebut bisa langsung dimasukkan pada software akuisisi MBES secara teratur ataupun dimasukkan pada software pengolahan MBES. Perangkat lunak Elac (HDPpost and HDPedit) digunakan dalam tahap pengolahan data. Software tersebut digunakan untuk melakukan cleaning data, koreksi SVP, dan koreksi pasang surut sehingga produk akhir berupa data point clouds kemudian dihasilkan dan dapat digunakan untuk analisis lebih lanjut (Sade et al., 2011). Pelaksanaan survei pemetaan pada daerah Teluk Kabui dilakukan dengan melakukan lintasan melintang dari barat ke timur dimulai dari bagian utara teluk kemudian menuju bagian selatan teluk. Pada daerah Selat Sagewin, jalur survei batimetri dilakukan dengan melakukan lintasan memanjang alur selat, yaitu dari bagian barat ke timur (Gambar 6).

\subsection{Survei Oseanografi}

Pengukuran CTD (Conductivity, Temperature, Depth) merupakan kegiatan akuisisi data sifat - sifat fisik kolom air laut. Air laut yang terdiri dari garam - garam terlarut dapat mempengaruhi sifat fisis air laut seperti densitas, kompresibilitas, titik beku, dan suhu. Dua sifat yang ditentukan oleh salinitas secara praktis di laut adalah 
daya hantar listrik (konduktivitas) air laut dan tekananstandar 1 atm pada larutan Kalium. Lewis (1980) secara lebih detil menjelaskan masing - masing komponen sebagai berikut:

\section{- Salinitas}

Salinitas merupakan jumlah seluruh garam-garaman (dalam satuan gram) pada satu kilogram air laut. Pada awalnya, penentuan harga salinitas dilakukan dengan meninjau komponen yang terpenting yaitu klorida $(\mathrm{Cl})$. Berdasarkan hasil pengukuran pada sampel air laut, terdapat hubungan antara salinitas dan klorida. Seiring perkembangan dalam teknik pengukuran konduktifitas, temperatur dan tekanan, penelitian dalam pendefinisian salinitas terus menerus disempurnakan. Sejak tahun 1978, salinitas didefinisikan sebagai suatu satuan yang baru yaitu Practical Salinity Scale, 1978 (PSS 78). Beberapa oseanografer menggunakan satuan "psu" dalam menuliskan harga salinitas, yang merupakan singkatan dari "practical salinity unit".

Pada kajian ilmu oseanografi dikenal dua istilah untuk menentukan suhu air laut yaitu suhu dan suhu potensial. Suhu adalah sifat termodinamis cairan yang disebabkan oleh aktivitas molekul dan atom di dalam cairan tersebut. Semakin besar aktivitas (energi), semakin tinggi pula suhunya. Di laut, biasanya digunakan permukaan laut sebagai tekanan referensi untuk suhu potensial. Sehingga kita membandingkan harga suhupada level tekanan yang berbeda jika parsel air telah dibawa ke permukaan laut tanpa percampuran dan difusi. Karena tekanan di atas permukaan laut adalah yang terendah (jika dibandingkan dengan tekanan di kedalaman laut yang lebih dalam), maka potensial (yang dihitung pada tekanan permukaan) akan selalu lebih rendah daripada suhu sebenarnya.

\section{- Konduktivitas}

Konduktivitas air laut bergantung pada jumlah ion-ion terlarut per volumenya dan mobilitas ion-ion tersebut. Satuannya adalah $\mathrm{mS} / \mathrm{cm}$ (milli-Siemens per centimeter). Konduktivitas bertambah dengan jumlah yang sama dengan bertambahnya salinitas sebesar 0.01, temperatur sebesar 0.01 dan kedalaman sebesar 20 meter. Secara umum, faktor yang paling dominan dalam perubahan konduktivitas di laut adalah temperatur.

\section{- Densitas}

Densitas termasuk parameter penting dalam mempelajari dinamika laut. Perbedaan densitas yang kecil secara horisontal (misalnya akibat perbedaan pemanasan di permukaan) dapat menghasilkan pergerakan massa air (arus)yang cukup kuat. Oleh karena itu penentuan densitas merupakan hal yang cukup penting dalam oseanografi. Lambang yang digunakan untuk menyatakan densitas adalah $\rho$. Densitas air laut bergantung pada temperatur (T), salinitas (S) dan tekanan (p). Kebergantungan ini dikenal sebagai persamaan keadaan air laut (Equation of State of Sea Water). Densitas bertambah dengan bertambahnya salinitas dan berkurangnya temperatur, kecuali pada temperatur di bawah densitas maksimum.

\section{- Tekanan (Kedalaman Laut)}

Tekanan air laut bertambah terhadap kedalaman. Kedalaman yang diukur dengan menggunakan CTD didasarkan pada harga tekanan. Tekanan didefinisikan sebagai gaya per satuan luas. Seperti telah disebutkan di atas, semakin ke dalam, tekanan air laut akan semakin besar. Dalam oseanografi, satuan tekanan yang digunakan adalah desibar 
(disingkat dbar), dimana $1 \mathrm{dbar}=10^{-1} \mathrm{bar}=10^{5} \mathrm{dynes} / \mathrm{cm}^{2}=10^{4}$ Pascal. Tekanan pada satu kedalaman bergantung pada massa air yang berada di atasnya.

Menurut Nichols \& Williams (2009), terdapat tiga parameter yang penting dalam menggambarkan kondisi suatu perairan yaitu temperatur, salinitas, dan tekanan. Pengukuran ketiga parameter tersebut dapat sekaligus dilakukan dengan menggunakan suatu alat, yaitu CTD (Conductivity, Temperatur, Depth)Profiler. Pada penelitian ini, data pengukuran CTD selain dapat dimanfaatkan untuk analisa karakteristik massa air suatu perairan, juga dapat digunakan sebagai input koreksi dalam survei batimetri (pemetaan dasar laut) menggunakan multibeam.

Nichols \& Williams (2009) juga menjelaskan metode pengambilan data CTD terbagi menjadi dua, yaitu real-time dan self-recording. Dalam metode real-time, data diambil secara langsung ketika alat diturunkan kedalam air. Sedangkan pada metode self-recording, data diambil dengan cara mendownload setelah alat diangkat dari dalam air. Tipe CTD profiler yang digunakan pada survei ini adalah Sea Bird-SBE911plus (Gambar 4(a)) dengan menggunakan metode real-time. SBE 911plus merupakan alat yang digunakan untuk mengukur berbagai parameter oseanografi. Alat ini mengukur konduktifitas, temperature, dan tekanan serta dapat mengukur parameter lain dengan menambahkan sensor lainnya hingga sebanyak 8 sensor tambahan. Alat tersebut dapat mengukur temperatur dengan ketelitian $2 \times 10^{-4}{ }^{\circ} \mathrm{C}$, dan conductivity dengan ketelitian $4 \times 10^{-5} \mathrm{Sm}^{-1}$ (Vladoiu et al., 2018). Sebelum diluncurkan ke dalam air, alat CTD dikonfigurasi terlebih dahulu agar data yang dihasilkan sesuai dengan kebutuhan (Gambar 4(b)). Alat CTD yang telah dikonfigurasi, lalu dirangkai pada frame untuk diluncurkan ke kedalaman tertentu dengan menggunakan winch yang terdapat di KR Baruna Jaya IV. Setelah CTD berada dalam air, data dapat secara langsung dilihat pada monitor komputer akuisisi. 


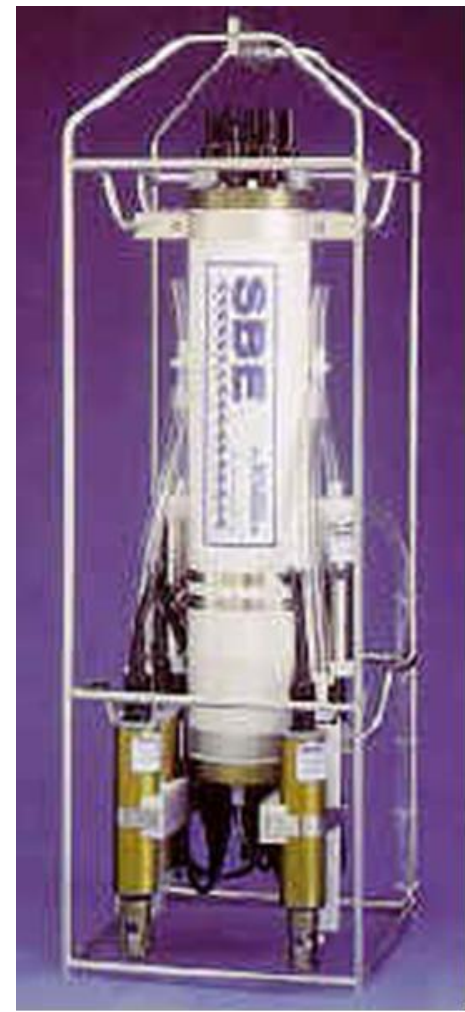

(a)
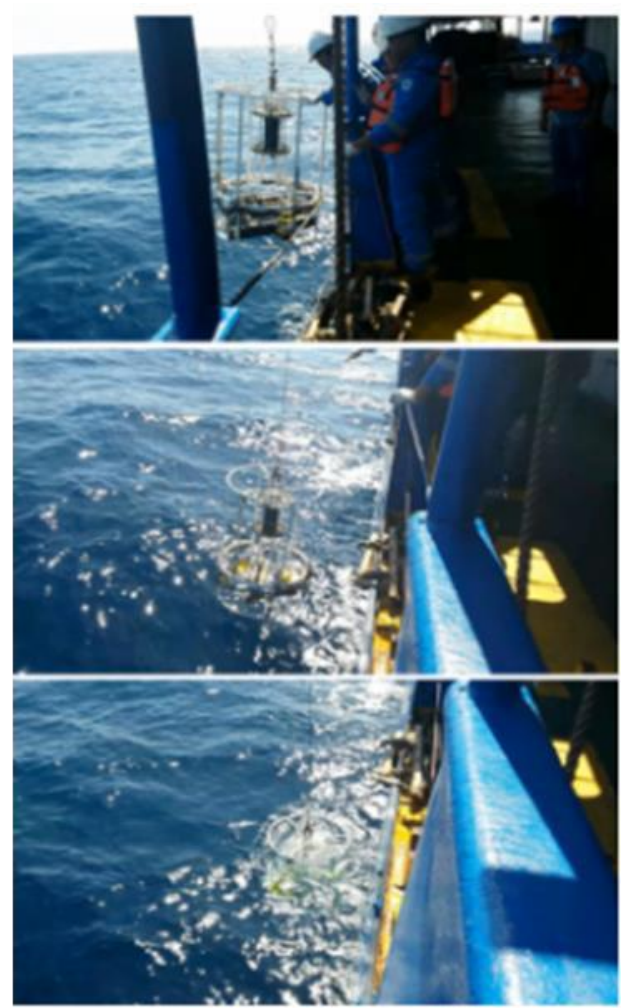

(b)

Gambar 4. CTD SBE 911plus (a), proses pengukuran CTD menggunakan frame (b)

\subsection{Sub Bottom Profiler}

Sub bottom profiler merupakan alat yang dapat digunakan dalam mengidentifikasi perlapisan sedimen pada permukaan laut. Target yang ingin dicapai dengan menggunakan alat ini adalah perlapisan sedimen yang terdapat pada dekat permukaan dasar laut, oleh karena itu sub bottom profiler sering juga disebut dengan seismik dangkal atau Shallow Seismic Reflection Profiling.

Menurut Penrose et al. (2005), kondisi lapisan sedimen bawah permukaan laut memiliki sifat fisis yang beragam. Tingkat kekerasan batuan bawah permukaan bumi merupakan salah satu sifat fisika yang dapat diketahui melalui pengukuran di permukaan bumi. Sub Bottom Profiler digunakan untuk mengidentifikasi lapisanlapisan sedimen di bawah permukaan dasar laut. Jenis lapisan sedimennya dapat diprediksi berdasarkan pola refleksi gelombang akustiknya. Selain jenis lapisan sedimen, informasi ketebalan lapisan sedimennya juga bisa didapat. Secara umum, ilustrasi prinsip pengukuran SBP dapat dilihat pada Gambar 5.

Sistem SBP Orotech 3010 digunakan pada penelitian ini. Transducer alat tersebut terpasang permanen pada lunas (hull-mounted) KR Baruna Jaya IV. Orotech 3010 termasuk kedalam sistem SBP berjenis pinger dan beroperasi pada frekuensi $3.5 \mathrm{kHz}$. Sistem SBP pinger termasuk kedalam kategori sistem sub bottom profiler berfrekuensi tinggi $(1542 \mathrm{~m} / \mathrm{s})$ dengan penetrasi dangkal dan mempunyai resolusi yang tinggi.Penetrasi maksimal dari gelombang akustik alat ini mencapai 95 milisecond (ms) dengan kedalaman 73.2 meter. Pengolahan data SBP dilakukan dengan menggunakan software Sonar Wiz Map Office yang dapat memberikan gambaran tomografi 2 dimensi. Tahapan pengolahan data diawali dengan import data SBP dan melakukan playback data pada SonarWiz Map. Selanjutnya pengolahan data dilakukan untuk membedakan antara sinyal dengan noise, sehingga dapat diketahui sinyal yang berasal 
dari gelombang refleksi. Tahap terakhir adalah tahap picking sequence untuk menginterpretasi layer lapisan sedimen.

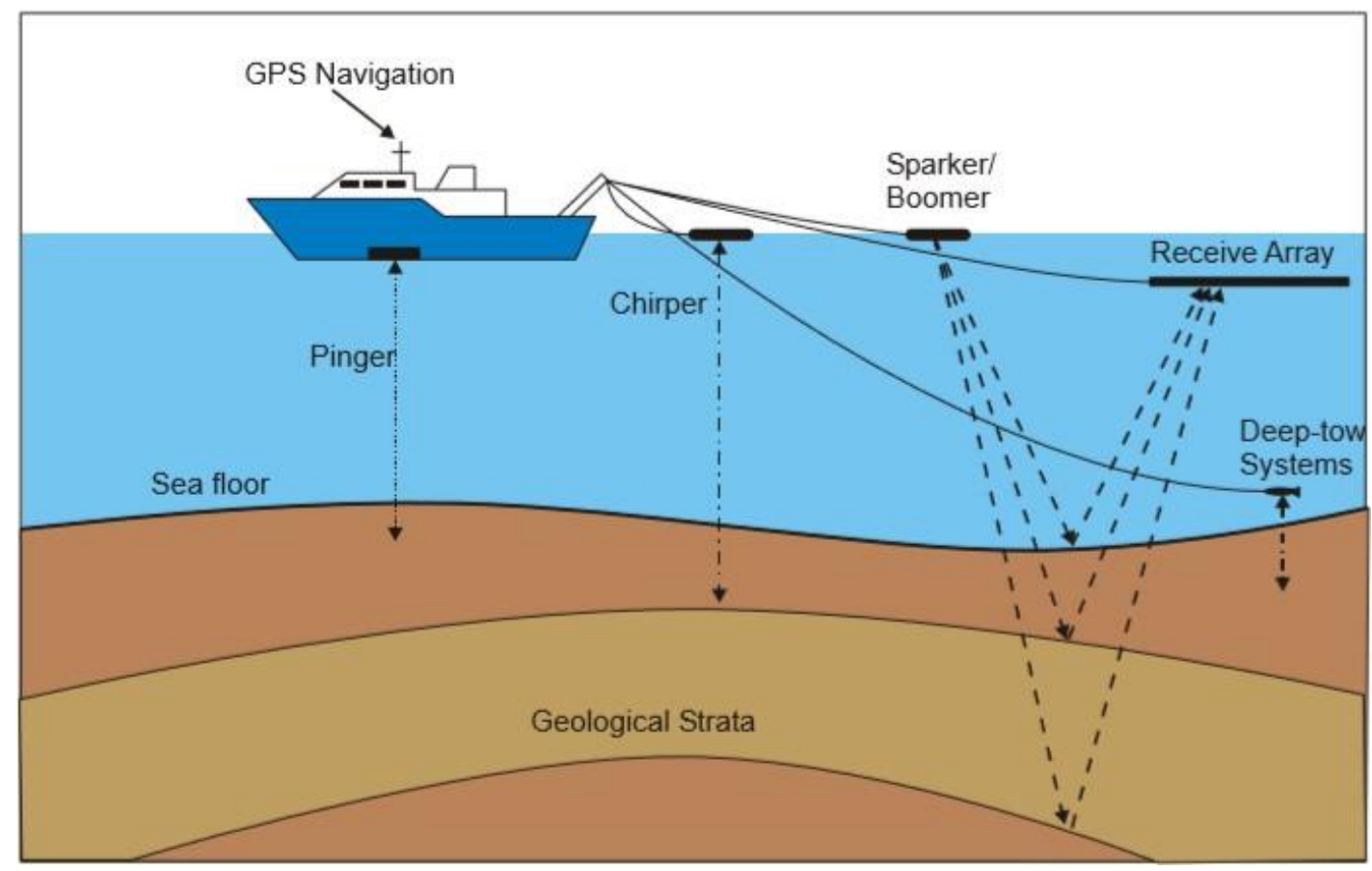

Gambar 5. Prinsip kerja SBP (Sumber :Penrose et al., 2005).

\section{HASIL DAN PEMBAHASAN}

\subsection{Batimetri}

Pada kegiatan survei batimetri, perencanaan lajur survei merupakan hal yang penting. Perencanaan lajur survei tersebut harus memperhitungkan perkiraan kedalaman laut di area survei agar didapatkan hasil pertampalan (overlap) antar lajur yang baik dan tidak ada celah (gap) kosong. Hasil rekaman jejak kapal pada saat akuisisi data berdasarkan lajur survei yang telah dibuat dapat dilihat pada Gambar 6 .

Data batimetri didapatkan setelah melalui tahap pemrosesan data. Gambar 7 merupakan hasil plot data batimetri hasil pengolahan data. Data batimetri tersebut memuat informasi kedalaman mulai dari yang terdangkal sampai yang terdalam berkesesuaian dengan warna secara berturut-turut dan bergradasi yaitu warna merah, warna kuning, warna hijau, warna biru, dan warna ungu (Gambar 7 (a) sampai dengan (d)). Kedalaman maksimum digambarkan dengan warna hijau yaitu $44 \mathrm{~m}$ hingga $53 \mathrm{~m}$, sementara kedangkalan minimum tergambarkan dengan warna biru. Dari hasil pengolahan tersebut didapatkan informasi kedalaman yang terdapat di wilayah Teluk Kabui adalah bervariasi antara 18 hingga 53 meter dari rata - rata permukan laut. Rata rata kedalaman di wilayah tersebut adalah kedalaman 35 meter yang cukup mendominasi di bagian tengah dari Teluk Kabui yang dapat ditunjukkan dengan dominasi warna hijau di peta daerah tersebut (Gambar 7(a) dan (c)). Secara umum morfologi dasar laut di sekitar kepulauan Raja Ampat sangat bervariasi dengan profil mendangkal pada bagian utara yang kemudian semakin dalam kearah selatan. Gambaran tersebut sesuai dengan kondisi topografi daratannya, dimana pada bagian utara teluk Kabui adalah daerah berbukit dan pada bagian selatan merupakan daerah mulut teluk yang relatif dangkal. 


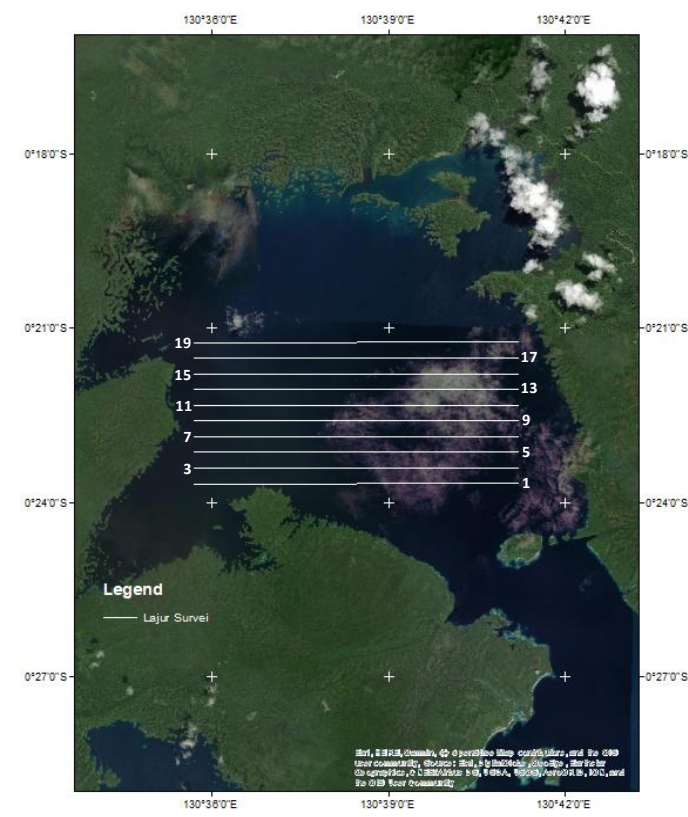

(a)

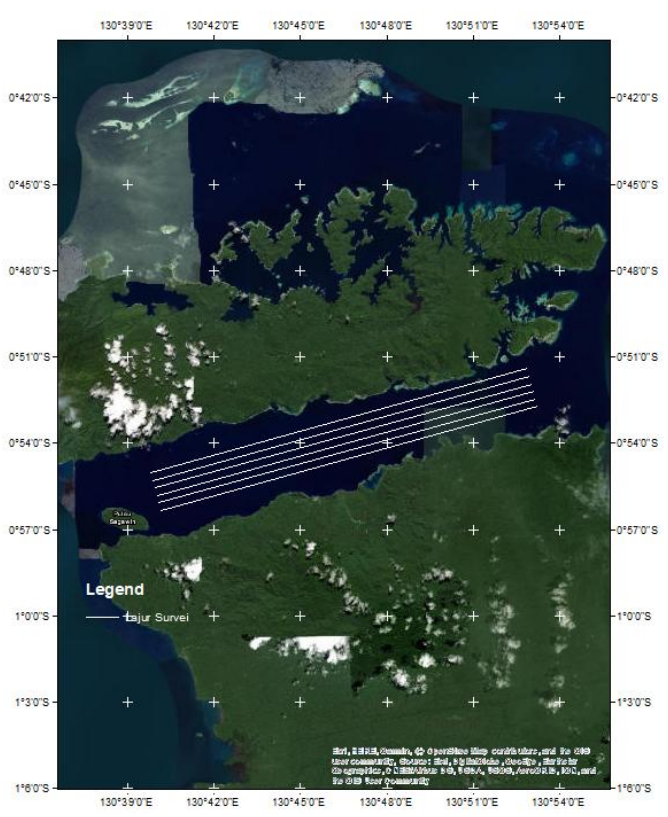

(b)

Gambar 6. Plot jejak kapal sesuai lajur survei (a) lokasi Teluk Kabui, (b) lokasi Selat Sagewin.

Selain peta batimetri di Teluk Kabui, kegiatan penelitian tersebut juga melakukan pemetaan di Selat Sagewin. Hasil survei multibeam di area tersebut dapat dilihat pada Gambar 7 (b), (d), (f). Selat Sagewin memiliki lebar lebih dari 2 km dan panjang sekitar $35 \mathrm{~km}$. Dari profil batimetri diperoleh informasi kedalaman yang terdapat di wilayah tersebut adalah 104 hingga 508 meter. Profil batimetri di Selat Sagewin memiliki ciri khas daerah selat dimana bagian tengah selat lebih dalam dengan bagian utara dan selatannya lebih dangkal (bentukan lembah). Permana \& Gaol (2018) menjelaskan bahwa morfologi lembah sempit tersebut dibatasi oleh karakteristik dinding terjal di dasar selat bagian utara dan endapan lunak sedimen di sisi bagian selatan selat. Perbedaan karakteristik batas selat tersebut mewakili perbedaan morfologi Pulau Batanta di bagian utara Selat dan Pulau Salawati di bagian selatan Selat.

Peta batimetri kedua area di wilayah Raja Ampat tersebut juga dikonfirmasi oleh Permana \& Gaol (2018). Mereka melakukan studi geologi di wilayah yang sama dan menemukan bahwa wilayah tersebut dicirikan oleh morfologi paparan dan direpresantasikan pada peta batimetri (Gambar 8). Peta tersebut menunjukkan gambaran batimetri di Kepulauan Raja Ampat yang diwakili dengan garis kontur dan warna. Dapat diketahui bahwa Kepulauan Raja Ampat merupakan paparan dengan kedalaman kurang dari 200m dan diwakili dengan warna hijau. Morfologi tersebut mencirikan Pulau Salawati dan Pulau Misool sebagai bagian Paparan Kepala Burung Papua yang kemudian menerus ke wilayah Kepulauan Raja Ampat. Mereka juga menjelaskan bahwa Selat Sagewin yang merupakan lembah dalam diantara Pulau Sawalati dan Pulau Batanta merupakan Sesar aktif Sorong. 

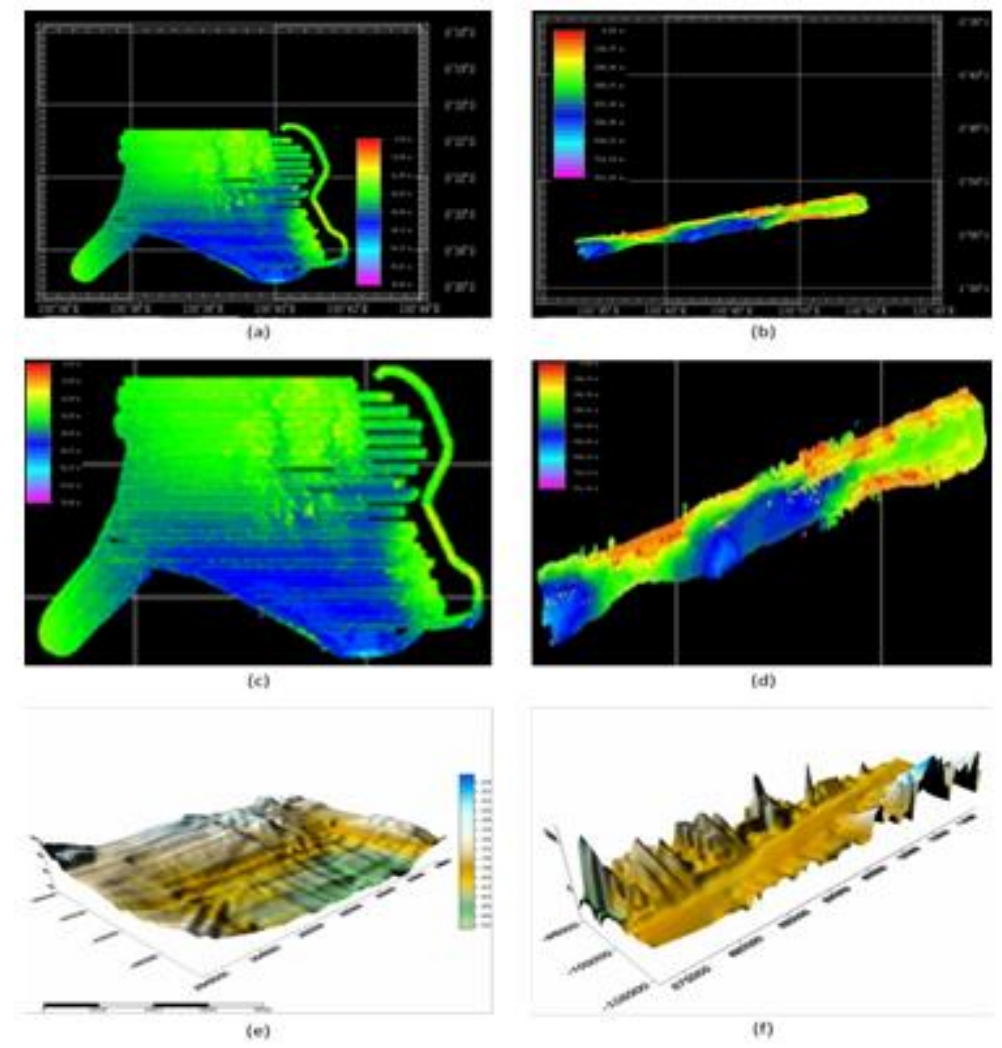

Gambar 7. (a) Hasil survei batimetri di Teluk Kabui, (c) Perbesaran gambar batimetri di Teluk Kabui, (e) Tampilan 3D batimetri Teluk Kabui, (b) Hasil survei batimetri di Selat Sagewin, (d) Perbesaran gambar batimetri di Selat Sagewin, (f) Tampilan 3D batimetri Selat Sagewin 


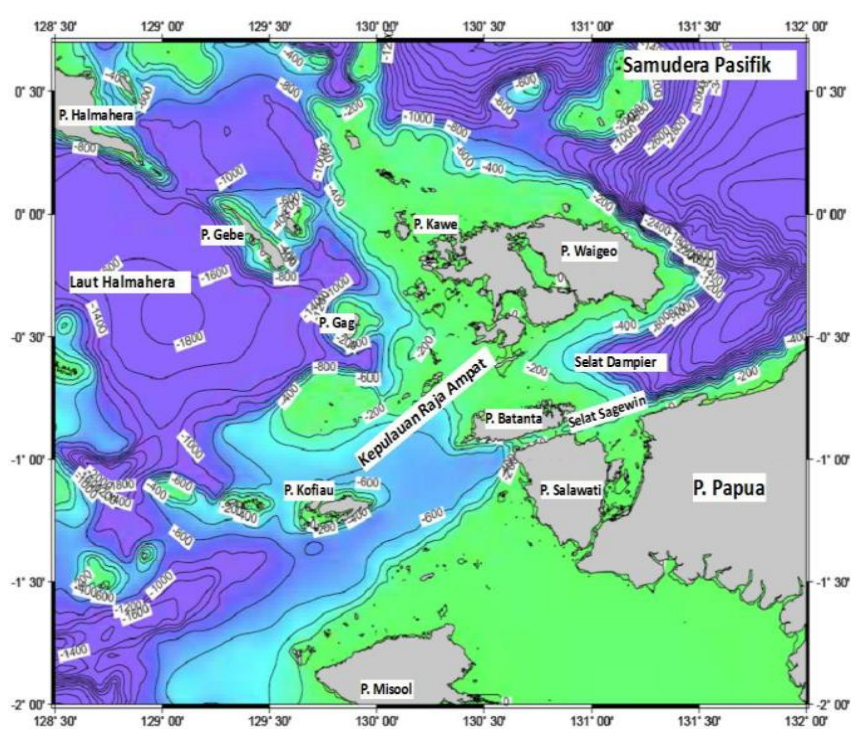

Gambar 8. Batimetri regional daerah Kepala Burung Papua dan Kepulauan Raja Ampat (Sumber: Permana \& Gaol, 2018).

\subsection{Oseanografi}

Kegiatan survei oseanografi di perairan Raja Ampat dapat digambarkan pada peta lokasi pengambilan sampel seperti terlihat pada Gambar 9. Metode yang digunakan dalam menganalisa data oseanografi pada penelitian ini adalah dengan mengolah data spasial primer yang diperoleh dari Ekspedisi Riset Kelautan Sail Raja Ampat Balai Teknologi Survei Kelautan.

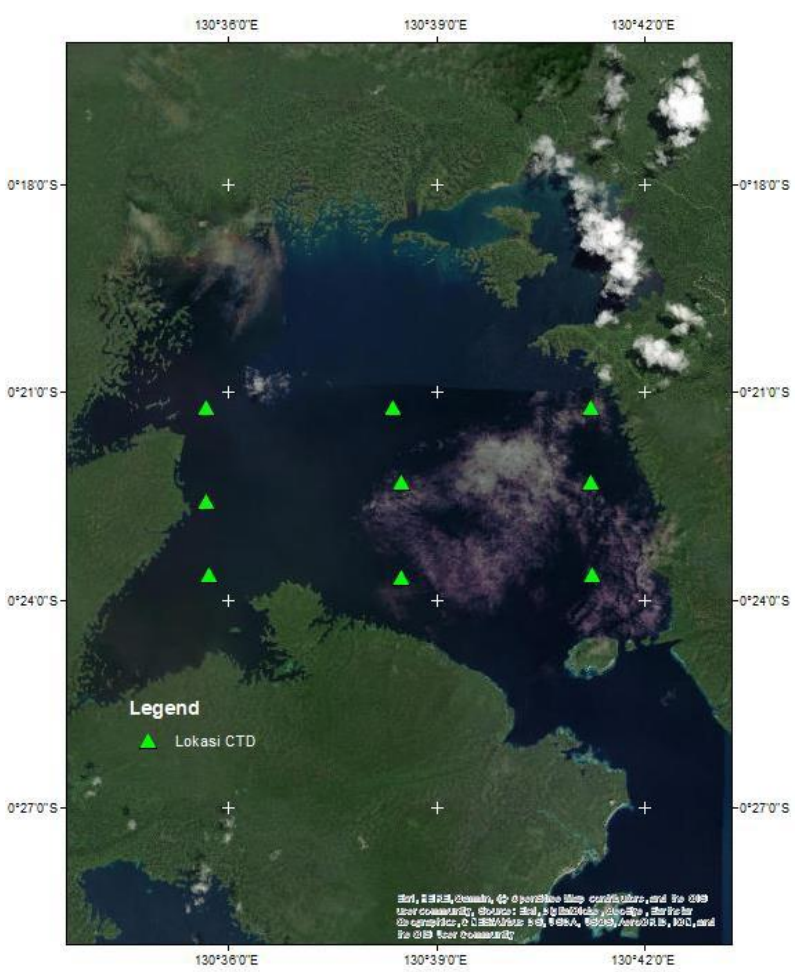

Gambar 9. Lokasi pengambilan sampel CTD di Teluk Kabui. 
Gambar 10 menunjukkan grafik sebaran suhu dan salinitas di teluk Kabui, Raja Ampat. Grafik pada kesembilan stasiun pada sekitar Teluk Kabui, perairan Kepulauan Raja Ampat tersebut menunjukan nilai temperatur yang seragam terhadap kedalaman. Dengan kedalaman rata-rata 25 - 45m maka hanya diperoleh profil mixed layer, dimana temperatur memiliki nilai kisaran yang sama dengan temperatur permukaan. Dari hasil CTD 9 stasiun di Teluk Kabui diperoleh rata-rata temperatur berkisar antara 29.2 $30.5^{\circ} \mathrm{C}$. Untuk nilai salinitas diperoleh nilai rata-rata berkisar antara 31 - 34 PSU. Pada ke-9 stasiun CTD di Teluk Kabui tidak terdapat lapisan thermocline. Hal ini disebabkan dangkalnya perairan di Teluk Kabui Raja Ampat sehingga hanya diperoleh lapisan mixed layer. Menurut Nugraha et al. (2018), perairan Raja Ampat dipengaruhi oleh "Indonesian-throughflow" dan juga dipengaruhi oleh musim sehingga mempengaruhi nilai suhu dan salinitas perairan. Sehingga studi tentang parameter - parameter fisik perairan seperti konduktivitas, suhu, dan salinitas dapat berperan penting dalam memahami karakteristik perairan di wilayah Raja Ampat.
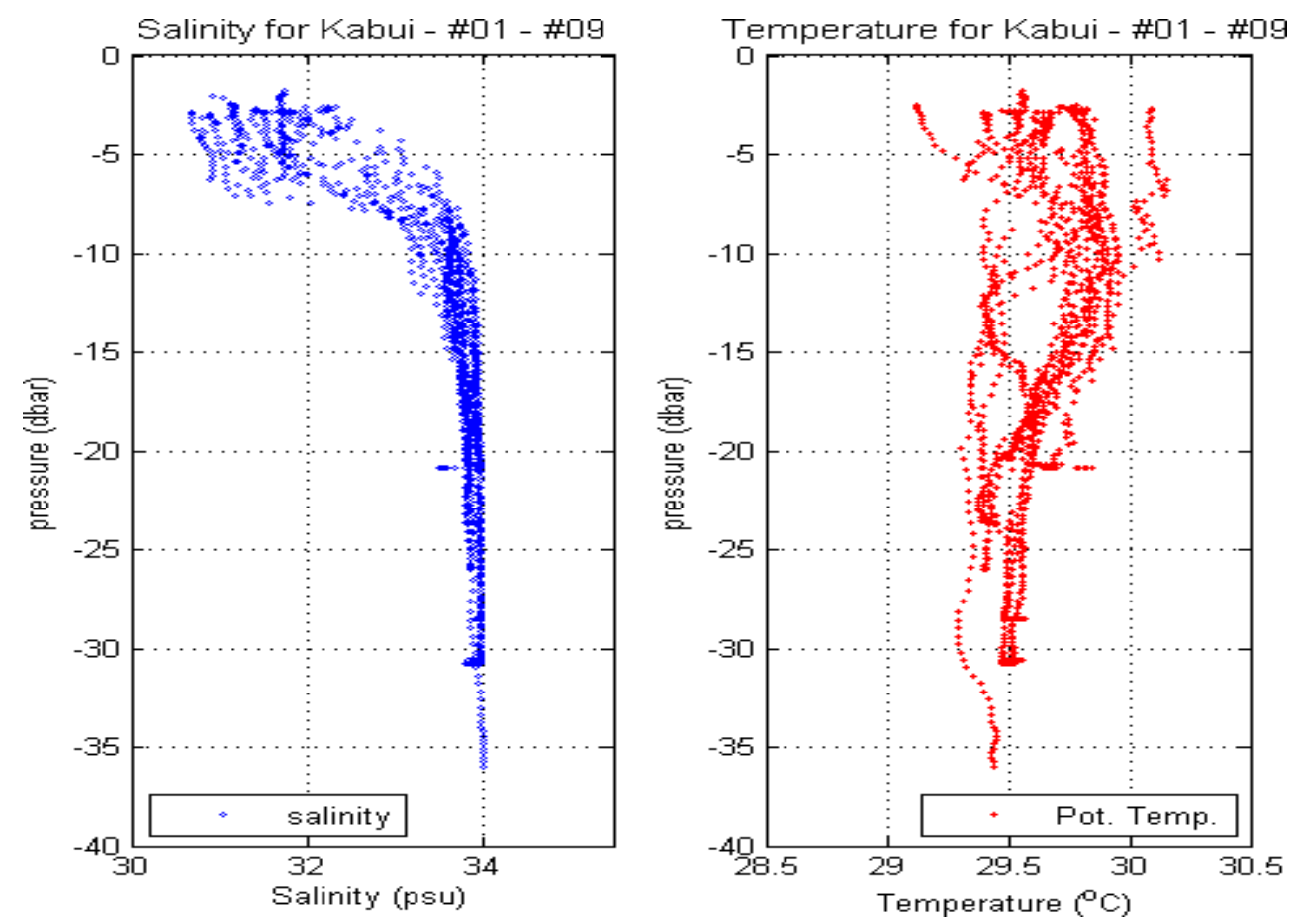

Gambar 10. Profil vertikal salinitas (kiri) dan Suhu potential(kanan) hasil pengamatan CTD sebanyak 9 stasiun (stasiun K-1 s.d. K-9) di Teluk Kabui.

\subsection{Sub Bottom Profiler}

Survei sub bottom profiler (SBP) dilakukan di Teluk Kabui selama tiga hari. Lintasan SBP mengikuti lintasan survei batimetri karena adanya keterbatasan waktu survei. Lintasan survey dibuat dengan arah barat - timur dengan SBP diambil pada lokasi Teluk Kabui dengan arah heading rata - rata kapal sekitar $275^{\circ}$ hingga $90^{\circ}$. Penamaan lintasan mengikuti penamaan lintasan survei batimetri (Gambar 6(a)) dimulai dengan lintasan ganjil $(21,17,15)$ kemudian lintasan genap $(4,6,8,10)$. Meskipun demikian kekurangan lintasan pada survei SBP adalah tidak adanya lintasan cross line yang memotong lintasan in-line pada teluk kabui sehingga tidak bisa dilakukan korelasi. Untuk mendapatkan gambaran geologi yang lengkap, diperlukan adanya komparasi dengan data yang lain dan pembuktian interpretasi lebih lanjut. Oleh karena itu dibutuhkan data seperti peta batimetri, side-scan sonar, dan data sampel coring untuk memperkuat data interpretasi SBP. 


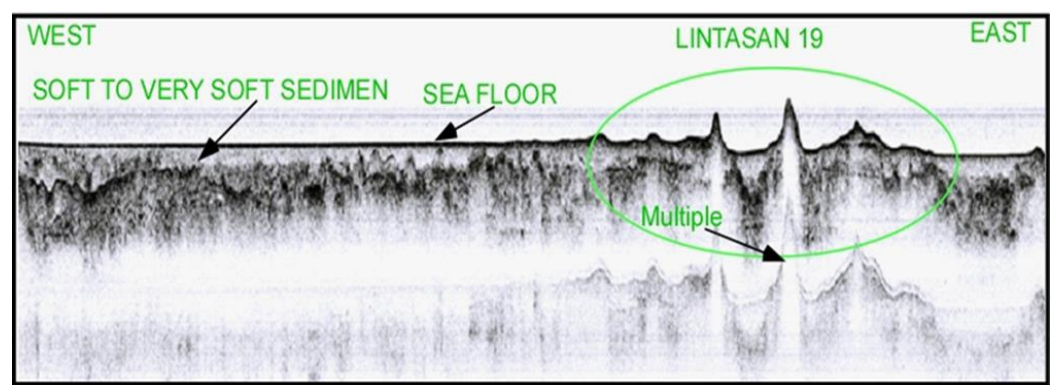

(a)

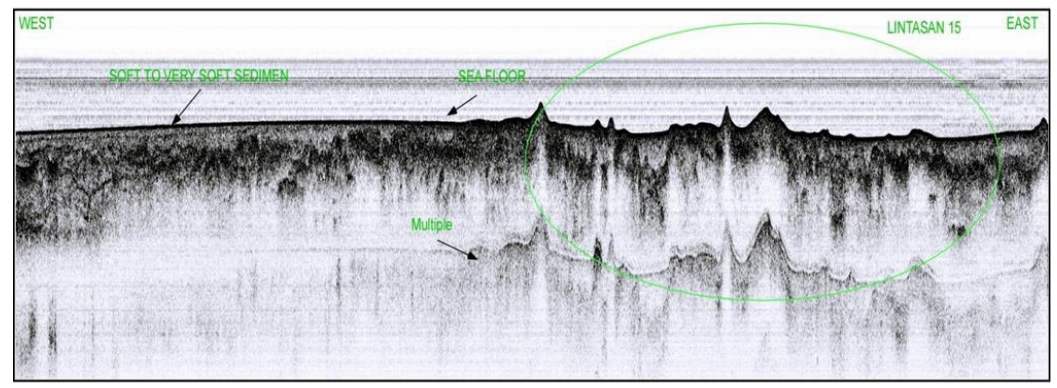

(b)

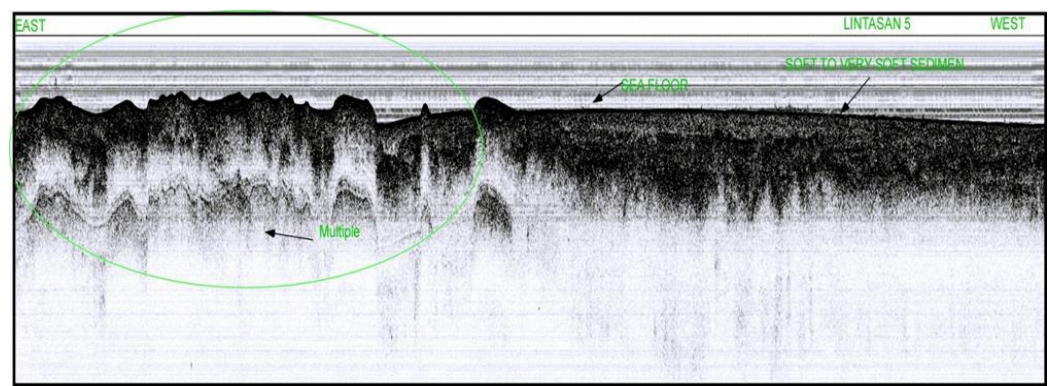

(c)

Gambar 11. Hasil rekaman SBP: (a) lintasan 19, (b) lintasan 15, dan (c) lintasan 5.

Dari hasil data SBP lintasan 19, 15, dan 5 (Gambar 11), dapat diinterpretasikan bahwa morfologi Teluk Kabui semakin ke arah timur adalah bergelombang dan berundulasi, dan sebaliknya semakin ke arah barat semakin bertopografi datar. Dari beberapa lintasan banyak terdapat bukit soliter yang diinterpretasikan sebagai batu gamping terumbu. Secara umum dapat terlihat 2 unit sequence yang terdapat pada lintasan Teluk Kabui. Sequence ini dibatasi oleh ketidakselarasan.

Sequence unit 1 dapat diinterpretasikan sebagai sedimen lunak dan terendapkan setelah terjadi erosi batuan sedimen dibawahnya. Sedimen ini banyak dijumpai di beberapa lintasan pada Teluk Kabui menunjukan tingkat erosi yang cukup berpengaruh. Pada bagian atas unit 1 dibatasi oleh permukaan laut sedangkan bagian bawah dibatasi oleh ketidakselarasan. Ketebalan unit 1 tidak menerus dan banyak yang mengisi pada posisi cekungan di beberapa tempat. Unit 1 ini diinterpretasikan mempunyai litologi soft sedimen sampai very soft sedimen. Sedimen tersebut dimungkinkan besar berumur endapan recent. Sequence unit 2 dibatasi oleh ketidakselarasan pada bagian atasnya dan bagian bawahnya tidak terlihat. Ketebalan unit ini tidak bisa ditentukan kareana tidak terlihat batas bawahnya. Secara litologi diinterpretasikan batuan sedimen berupa batupasir dan batugamping. Interpretasi litologi tersebut juga dikonfirmasi oleh Gisland et al. (2017), yang melakukan penelitian geolistrik di wilayah daratan Raja Ampat dan 
mereka juga menemukan hasil bahwa adanya kesamaan litologi batuan berupa batupasir dan lempung. Walaupun studi mereka tidak mencakup wilayah perairan Raja Ampat, namun dari peta geologi regional (Gambar 12) dapat dilihat bahwa struktur sedimen geologi di Raja Ampat mempunyai karakteristik yang sama dan menerus dari Waigeo sampai dengan daerah Kepala Burung bagian utara.

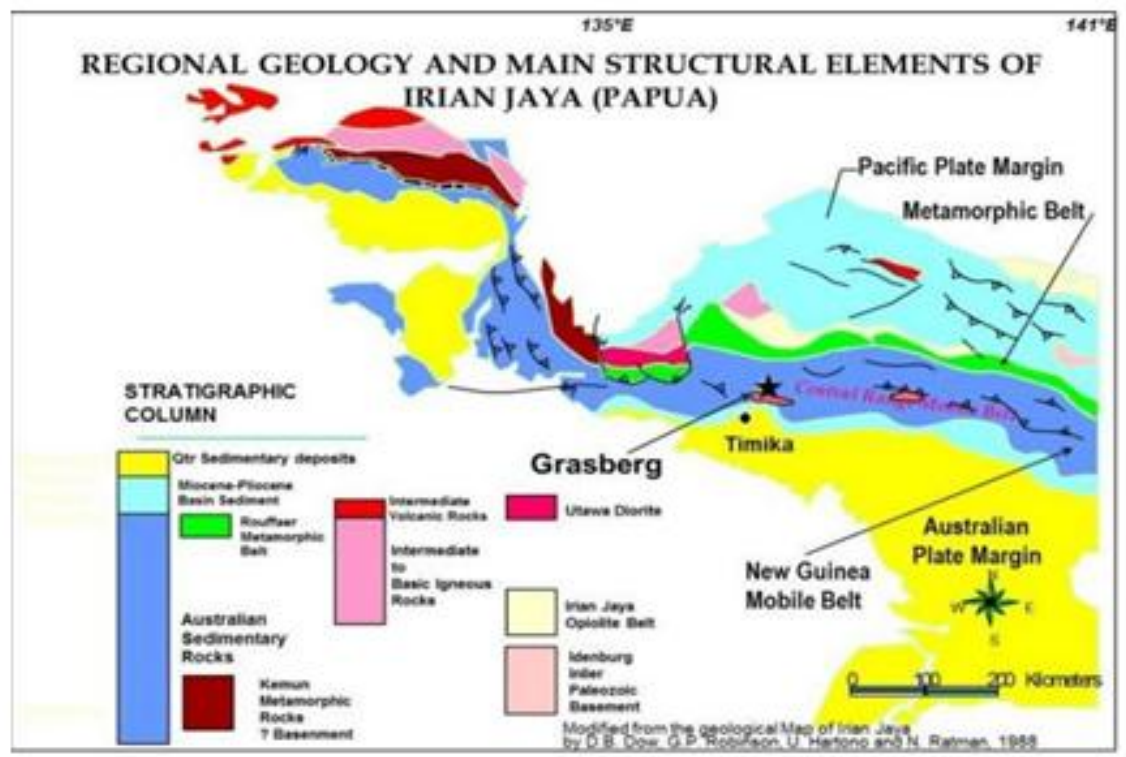

Gambar 12. Geologi Regional Daerah Papua (Sumber: Aiwoy et al.(2018)).

\section{KESIMPULAN}

Penelitian ini dimaksudkan untuk memberikan deskripsi survei hidro-oseanografi di perairan Raja Ampat sebagai bagian dari kegiatan Sail Raja Ampat 2014. Survei tersebut dilakukan menggunakan KR Baruna Jaya IV dari tanggal 17 Agustus sampai dengan 20 September 2014 dengan beberapa kegiatan survei yang dilakukan. Tiga kegiatan survei utama yaitu survei batimetri multibeam, survei oseanografi CTD, dan survei sub bottom profiler dibahas dalam penelitian ini. Dalam penelitian ini, kegiatan survei tersebut dilakukan pada dua area utama di perairan Raja Ampat yaitu Teluk Kabui dan Selat Sagewin. Hasil survei menunjukkan bahwa secara batimetri wilayah Teluk Kabui memiliki kedalaman bervariasi antara 18 sampai dengan 53 meter dengan kedalaman rata - rata sekitar 35 meter di bagian tengah teluk. Sedangkan wilayah Selat Sagewin yang berupa kanal sempit selebar $2 \mathrm{~km}$ dan sepanjang $35 \mathrm{~km}$, memiliki kedalaman antara 104 hingga 508 meter. Dari hasil pengukuran CTD pada periode Agustus-September 2014 diketahui bahwa perairan Raja Ampat memiliki rata - rata suhu berkisar $29.2-30.5^{\circ} \mathrm{C}$ dengan nilai salinitas sebesar $31-34$ psu. Hasil survei SBP dan literatur geologi juga dapat diketahui bahwa secara umum wilayah perairan di area survei memiliki litologi berupa batupasir, batugamping, dan lempung.

\section{UCAPAN TERIMAKASIH}

Penulis beserta rekan mengucapkan terima kasih kepada pihak manajemen Balai Teknologi Survei Kelautan, Badan Pengkajian dan Penerapan Teknologi (BPPT) atas dukungan dan ijin pemakaian data dan laporan hasil survei Sail Raja Ampat 2014. 


\section{DAFTAR PUSTAKA}

Aiwoy, F. ., Safri, I., \& Yuningsih, E. T. (2018). Kontrol Mineralogi Terhadap "Problematic Ore" Cadangan Grasberg Block Cave (GBC) Tambang Bawah Tanah Freeport Indonesia di Papua. Bulletin of Scientific Contribution: Geology, 16(1), 18.

Codaoctopus. (2020). Coda Octopus F180® Series. Retrieved October 24, 2020, from https://www.codaoctopus.com/products/motion/f180

Donnelly, R., Neville, D., \& Mous, P. J. (2003). Report on a rapid ecological assessment of the Raja Ampat Islands, Papua, Eastern Indonesia. Journal of Allied Health (Vol. 21). Bali.

Febriawan, H. K., Haryadi, Y., \& Nurwahyudy, A. (2020). Hydro-acoustic Survey and Edge-detection method in Investigation of a Passenger Vessel Accident in East Java, Indonesia. Buletin Oseanografi Marina, 9(1), 59-68. https://doi.org/10.14710/buloma.v9i1.29442

Gisland, G., Alam, B. Y. C. S., \& Nur, A. A. (2017). Potensi Akuifer Air Tanah Pada Batuan Sedimen Tersier Berdasarkan Analisis Data Geolistrik Di Distrik Waisai Kota Kabupaten Raja Ampat, Provinsi Papua Barat. Bulletin of Scientific Contribution, 15(2), 181-192.

Hukom, F. D., Yulianda, F., Bengen, D., \& Kamal, M. (2018). Reef fishes in the marine protected area of Dampier strait, raja ampat islands, West Papua Province, Indonesia. International Journal of Fisheries and Aquatic Studies, 6(6), 131-135.

Larsen, S. N., Leisher, C., Mangubhai, S., Muljadi, A., \& Tapilatu, R. F. (2018). Fisher perceptions of threats and fisheries decline in the heart of the Coral Triangle. Ocean Life, 2(2), 41-46. https://doi.org/10.13057/oceanlife/o020201

Lewis, E. L. (1980). The Practical Salinity Scale 1978 and Its Antecedents. IEEE Journal of Oceanic Engineering, 5(1), 3-8. https://doi.org/10.1109/JOE.1980.1145448

Nichols, C. R., \& Williams, R. G. (2009). Encyclopedia of Marine Science. Encyclopedia of Marine Science (Vol. 8). New York: Facts On File, Inc.

https://doi.org/10.1016/0308-597x(84)90087-3

Nugraha, A. P., Purba, N. P., Junianto, \& Sunarto. (2018). Ocean Currents , Temperature, and Salinity at Raja Ampat Islands and The Boundaries Seas. World Scientific News, 110(September), 197-209.

Papilaya, R. L., Boli, P., \& Nikijuluw, V. P. H. (2019). Carrying Capacity of Diving Tourism in Dampier Strait Marine Conservation Area - District of Raja Ampat. IOP Conference Series: Earth and Environmental Science, 246(1). https://doi.org/10.1088/1755-1315/246/1/012060

Penrose, J. D., Siwabessy, P. J. W., Gavrilov, A., Parnum, I., Hamilton, L. J., Bickers, A., ... Kennedy, P. (2005). Acoustic Techniques for Seabed Classification. Cooperative Research Centre for Coastal Zone Estuary and Waterway Management, (September), 141.

Permana, H., \& Gaol, K. L. (2018). Sesar Geser Sorong Segmen Sorong-Kofiau, Papua Barat, Indonesia: Bukti Dari Data Batimetri dan SBP. Jurnal Geologi Kelautan, 16(1), 37-50.

Priatna, A., \& Sadhotomo, B. (2011). Sebaran Plankton Dan Larva Ikan Di Perairan Kepulauan Raja Ampat: Kajian Metode Hidroakustik Dan Survei Konvensional. Bawal, 3(5), 345-350.

Sade, A. (Ronnie), Tibor, G., Hall, J. K., Diamant, M., Sade, H., Hartman, G., ... 
Markel, D. (2011). High resolution multibeam bathymetry of the Sea of Galilee (Lake Kinneret). Israel Journal of Earth Sciences, 58(2), 121-129. https://doi.org/10.1560/ijes.58.2.121

Vladoiu, A., Bouruet-Aubertot, P., Cuypers, Y., Ferron, B., Schroeder, K., Borghini, M., ... Ismail, S. Ben. (2018). Turbulence in the Sicily Channel from microstructure measurements. Deep-Sea Research Part I, 137, 97-112. https://doi.org/10.1016/j.dsr.2018.05.006 